\title{
Representasi Kearifan Lokal Jawara dalam Novel Kelomang (The Representation of the Champion's Local Wisdom in the Kelomang Novel)
}

\author{
Asep Muhyidin a,1 \\ ${ }^{\text {a }}$ Universitas Sultan Ageng Tirtayasa, Serang, Indonesia \\ ${ }^{1}$ muhyidin21@untirta.ac.id
}

Article info

Article history:

Received: 23-09-2019

Revised : 07-12-2020

Accepted: 17-02-2021

Keywords:

Kelomang novel local wisdom jawara character education

\section{A B S T R A C T}

The aim of this study is to examine how the champion's local wisdom is depicted in Qizink La Aziva's novel entitled Kelomang. The method used in this study is descriptive qualitative. The data sources are represented in the novel as words that describe the champion's local wisdom. The data were analyzed using qualitative descriptive techniques in three stages: categorization, tabulation, and inference. The study's findings show that the champion's figure in the novel's characters is good at selfdefence, courage, leadership, armed with machetes and agate, speaking candidly, and a culture of violence. In this novel, a black champion is depicted in the form of Sakib, who is always willing to justify any means to achieve his goal. The idea of a white champion, on the other hand, is portrayed in the character of Saija, who battles for the betterment of society. This study's findings may have implications for learning Indonesian in senior high schools. This is because there are learning components connected to character education in the 2013 Curriculum. The novel's good characters can serve as role models for students.

Penelitian ini bertujuan untuk mengetahui representasi kearifan lokal jawara dalam novel Kelomang karya Qizink La Aziva. Penelitian ini menggunakan metode yang bersifat deskriptif kualitatif. Data berupa kalimat-kalimat dalam novel yang menggambarkan kearifan lokal jawara. Analisis data dilakukan dengan teknik deskriptif kualitatif melalui beberapa tahapan, yaitu 1) kategorisasi, 2) tabulasi, dan 3) inferensi. Hasil penelitian menunjukkan representasi sosok jawara yang terdapat pada tokohtokoh yang ada pada novel tersebut bersifat jago bela diri, pemberani, berjiwa pemimpin, bersenjatakan golok dan memakai batu akik, berbicara ceplas-ceplos, dan budaya kekerasan. Dalam novel ini muncul sosok jawara hitam yang tergambar pada sosok Sakib yang selalu menghalalkan segala cara demi mendapatkan tujuannya. Sebaliknya, sosok jawara putih tergambar pada sosok tokoh Saija yang berjuang demi kepentingan masyarakat. Hasil penelitian ini dapat diimplikasikan dalam pembelajaran bahasa Indonesia di Sekolah Menengah Atas. Hal demikian disebabkan karena di dalam Kurikulum 2013 terdapat komponen-komponen pembelajaran yang berkaitan dengan penguatan pendidikan karakter. Siswa dapat meneladani karakter baik pada tokoh-tokoh yang ada pada novel tersebut.

Copyright $(2021$ Institut Agama Islam Negeri Syekh Nurjati Cirebon. All rights reserved. 


\section{PENDAHULUAN}

Jawara dan kiai dengan dibantu oleh masyarakat Banten pada masa kolonial saling bekerja sama dalam mengusir bangsa penjajah, pada saat itulah kearifan lokal jawara mulai dikenal (Cahyo, 2017; Pribadi, 2013). Pada era kolonial tersebut sosok jawara memiliki citra positif di mata masyarakat. Namun, seiring berjalannya waktu saat bangsa penjajah sudah tidak ada lagi, maka peran jawara mulai mengalami pergeseran. Pada era reformasi, pengakuan terhadap peran jawara mulai tumbuh terutama dalam menciptakan oligarki lokal di Banten dengan cara-cara yang terlarang (Pribadi, 2011). Kesan masyarakat terhadap sosok jawara mulai terasa tidak baik dan terjadi konotasi negatif terhadap istilah jawara di mata masyarakat pada umumnya (Cahyo, 2017).

Karya sastra merupakan cerminan atau gambaran pada zamannya dengan berbagai permasalahan dan tendensinya masing-masing (Yulianeta et.al, 2016). Novel sebagai sebuah jenis karya sastra pada dasarnya merupakan sebuah cerita dari gambaran sosial masyarakatnya (Sukarjo, 2014). Representasi sosial tersebut merupakan gambaran kehidupan masyarakat nyata, misalnya tentang kehidupan ekonomi, kesenjangan sosial, tingkat pendidikan, sosial budaya, maupun agama yang dianut. Novel sebagai sebuah kreativitas estetis berusaha merespons kehidupan masyarakat nyata, berusaha mengungkapkan perilaku manusia yang sebenarnya. Dimensi-dimensi yang direpresentasikan merupakan dimensi kehidupan dari sebuah komunitas masyarakat. Dimensi dari komunitas masyarakat yang dimaksud tentu saja berupa masyarakat tempat pengarang menemukan ide ceritanya (Sari \& Nuryatin, 2017).

Novel sebagai cerminan kehidupan bermasyarakat merupakan suatu karya yang dapat dinikmati oleh pembacanya dan dapat pula dimanfaatkan oleh masyarakat (Dewi \& Balawa, 2017). Novel sebagai sebuah genre sastra tercipta karena adanya pengalaman batin pengarang. Permasalahan nyata di masyarakat tempat pengarang hidup merupakan sumber imajinasi pengarangnya. Hal yang menarik menurut pandangan pengarang dituangkan dalam bentuk tulisan. Fenomena tersebut merupakan ikatan timbal balik antara karya sastra dengan masyarakat. Novel sebagai sebuah karya sastra juga mampu memberikan manfaat terutama pada dunia pendidikan, pembaca dapat mengambil amanat berupa nilainilai moral yang ada dalam ceritanya (Supriyantini \& Arifin, 2019).

Realitas sosial yang tidak terpantau oleh masyarakat dan sangat unik biasanya dijadikan sumber inspirasi oleh pengarang (Sari \& Nuryatin, 2017). Dalam hal ini, peran pengarang sangat penting dalam menjadikan karya sastra sebagai ensiklopedi sosial mini bagi pembaca tentang sebuah kehidupan sosial masyarakat tertentu. Novel sebagai sebuah karya fiksi menampilkan permasalahan kehidupan sehari-hari melalui karakter para tokoh yang terdapat di dalamnya. Karakter pemeran dalam tokoh-tokoh cerita merupakan representasi kehidupan masyarakat sehari-hari (Setiawan, Agustina, \& Chanafiah, 2019). Seorang pengarang menciptakan sebuah karya sastra fiksi termasuk novel biasanya tema yang muncul diambil dari realitas kehidupan, pengalaman orang lain yang dilihat dan didengar, ataupun hasil imajinasi saja (Mandrastuty, 2010). Sebagai sebuah bentuk fiksi, novel menyajikan sebuah dunia imajiner yang dibangun melalui penceritaan, penokohan, peristiwa unik, dan latar cerita yang bersifat imajiner (Nurgiyantoro, 2011).

Representasi merupakan sebuah konsep bagaimana dunia ini dikonstruksikan secara sosial kepada dan oleh kita (Barker, 2015). Representasi 
merupakan proses dinamis yang terus berkembang seiring dengan kemampuan intelektual manusia. Representasi merupakan produksi makna dari konsep-konsep yang ada dalam jiwa manusia ke dalam bahasa sebagai mediumnya (Pujiati, 2018). Pemaknaan konsep tersebut meliputi: 1) mental representation dan 2) language representation. Dengan demikian, representasi merupakan proses hubungan antara pembentukan makna antara objek tententu, konsep tertentu dan tanda tertentu.

Pendekatan reflektif merupakan cara kerja representasi. Diawali dengan pemahaman makna terhadap suatu objek, manusia, ide, ataupun peristiwa di dunia nyata. Pada akhirnya, bahasalah yang menjadi cermin dalam merefleksikan kebenaran makna yang telah ada di dunia (Hall dalam Chairiyani, 2012). Dalam istilah pendekatan sastra, konsep ini disebut mimetik yaitu bahasa merefleksikan kebenaran makna. Dengan demikian, novel yang akan dianalisis dalam tulisan ini dapat dipandang sebagai sebuah representasi. Dengan kata lain, novel sebagai objek merupakan situs konstruksi makna. Cerita dalam novel harus didudukkan dalam konteks masyarakat karena karya sastra adalah produk kultural pengarangnya.

Sebagai hasil komunikasi intensif pengarang dengan lingkungannya, novel dipandang mampu menampilkan realitas kehidupan yang nyata bahkan yang tersembunyi sekalipun (Ilma, 2016). Namun demikian, novel sebagai karya sastra tidak selamanya netral karena novel melihat realitas dari sudut pengarang. Kepentingan tertentu yang sifatnya implisit biasanya dimunculkan oleh pengarang dan bahkan ruang tempat ideologi beroperasi juga muncul dalam sebuah novel. Dengan demikian, novel sebagai karya sastra memiliki kekuatan untuk mengarahkan daya kognitif pembaca pada serangkaian pemahaman melalui simbol dan tanda untuk kemudian membentuk sikap yang mengarahkan khalayaknya pada ideologi tertentu. Oleh karena itu, penulis memandang bahwa novel tepat diteliti sebagai ruang representasi untuk diteliti secara saksama terkait kepentingan, maksud, dan makna yang ingin dihadirkan di balik nuansa penggambarannya.

Sastra merupakan realitas masyarakat (Istiqomah et.al, 2014). Semua teori sastra pada dasarnya berawal dari konsep mimesis yang bermakna perwujudan, jiplakan, dan peniruan dari realita. Tanpa realita, yaitu kehidupan sehari-hari, manusia, pemikiran, konflik, karya seni, termasuk sastra, tidak akan ada. Sastra menurut Damono (2013) menampilkan kehidupan mencakup hubungan antarmasyarakat, antara masyarakat dengan orang-seorang, antarmanusia, dan antarperistiwa yang terjadi dalam batin seseorang pengarang. Sementara dunia ekspresi berkaitan dengan pengarang yang menyajikan dunia itu kepada pembaca, dan pembaca adalah dunia penikmat yang membaca karya (Mukti, Andayani, \& Wardani, 2018). Pembaca memberi tanggapan atas karya sastra.

Jawara sendiri dikonotasikan sebagai seseorang yang semata-mata menggunakan ilmu hitam, misalnya ilmu kekebalan yang didapatkan dari dukun yang tentunya bukan ajaran agama (Pribadi, 2013). Pemaknaan jawara yang telah diuraikan tersebut tidak jauh berbeda dengan pernyataan bahwa jawara sebagai personil dan individu yang disegani dan dibenci oleh masyarakat tidak terlepas dari simbol dan atribut fisik jawara tersebut, sebagai pendekar yang pandai berkelahi dan tidak mempan senjata misalnya pisau serta memiliki ilmu magis, selalu berseragam hitam-hitam, dan sikapnya selalu waspada dengan senjata terselip di pinggang (Hamid, 2010). Saat ini, ada kecenderungan sosok jawara 
dikenal dalam arti simbolik yaitu orang-orang yang mengandalkan fisik semata, berani bertindak, sangat agresif, terbuka, dan berbicara sembarangan yang cenderung tidak sopan (Chairunnisa, 2017).

Jawara dalam kultur budaya Banten dapat dikatakan sebagai simbol kearifan lokal masyarakat. Peran sosial yang dilakukan oleh jawara adalah seputar kepemimpinan informal (Tihami, 2015). Karakter jawara dapat diamati dari tampilan yang militan, patriotik, dan fanatik. Sosok jawara digambarkan sebagai seseorang yang memiliki kadigjayaan (kesaktian) yang meliputi jenis-jenis kasereman (menakutkan) dalam penampilan sehingga ditakuti orang seperti memiliki kekebalan tubuh serta mahir berkelahi (Tihami, 2015). Para jawara ini terorganisasi dan memiliki pengikut sehingga mempunyai anak buah. Sang anak buah biasa bergerak dalam aktivitas kriminal. Untuk memperoleh kekuatan, kekebalan, dan bentuk kesaktian lainnya mereka mencari 'elmu' dari guru-guru silat atau ahli-ahli 'elmu kadigjayaan.' Sosok jawara memiliki karakter yang khas dengan pakaian hitam bersenjatakan golok di pinggang (Firdausi, 2016). Para jawara ada kecenderungan menyelesaikan masalah dengan kekerasan. Oleh karena itu, saat ini sebagian masyarakat memandang jawara sebagai sosok yang negatif (Ato'ullah, 2014).

Novel Kelomang karya Qizink La Aziva berlatar belakang budaya Banten yang dipenuhi realitas sosial yang terjadi pada masyarakat. Novel ini menceritakan terjadinya korupsi, kolusi, dan nepotisme yang terjadi pada masyarakat Banten, misalnya peristiwa tindakan suap-menyuap untuk perizinan proyek penambangan pasir laut. Sampai akhirnya ditangkap tangannya bupati dan pengusaha oleh KPK saat terjadi transaksi suap di sebuah hotel. Beberapa tokoh yang dimunculkan oleh pengarang diantaranya adalah Yanto, Saija, Ardi, dan Sakib. Yanto digambarkan sebagai seorang pemimpin redaksi sebuah koran yang jujur, misalnya tindakan berani yang menolak suap dari kliennya agar pemberitaan koran tersebut tidak mengangkat kasus korupsi salah seorang anggota keluarga pengusaha besar. Tokoh Saija merupakan seorang mahasiswa yang juga aktivis lingkungan. Ia menjadi pemimpin demo penolakan izin penambangan pasir laut sekaligus juga jago dalam bela diri. Tokoh Ardi yang pada awalnya adalah aktivis mahasiswa yang idealis. Namun, setelah lulus idealismenya menjadi luntur oleh gemerlapnya dunia bisnis dan menjadi anak buah Sakib. Kemudian, tokoh Sakib yang digambarkan sebagai seorang pengusaha besar yang menganut paham kawin cerai dan juga menghalalkan segala cara untuk memperoleh keuntungan dalam berbisnis.

Penelitian tentang representasi dalam novel telah dilakukan oleh pada penelitian terdahulu. Zulu (2012) meneliti representasi gender dalam novel Moeti wa Botjhabela. Dalam novel tersebut ditemukan kesetaraan gender antara laki-laki dan perempuan yang merepresentasikan budaya Sesotho. Kemudian, Wiyatmi (2013) melakukan penelitian tentang representasi sejarah Indonesia dalam novelnovel karya Ayu Utami. Representasi sejarah sosial politik muncul dalam novelnovel tersebut. Lalu, Hasanah (2017) melakukan penelitian tentang representasi femme fatale dalam novel Cantik Itu Luka karya Eka Kurniawan. Hasil penelitian menunjukkan bahwa tokoh-tokoh yang dianalisis merepresentasikan beberapa karakteristik yang dapat dinamakan sebagai femme fatale.

Mu'jizah (2014) dalam artikelnya "Representasi Anak dalam Karya Arswendo Atmowiloto: Studi Cerita Anak Tahun 1970-an" menemukan bahwa pengarang menyajikan dunia anak yang khas berupa cerita kemandirian anak. 
Kemudian, Ilma (2016) melakukan penelitian tentang representasi penindasan ganda dalam novel Mirah dari Banda berdasarkan perspektif feminisme pacsakolonial. Hasil penelitian menunjukkan bahwa novel tersebut mewacanakan kedudukan inferior perempuan akibat dominasi sistem kolonialisme serta dominasi patriarki baik lelaki kolonial maupun pribumi. Selanjutnya, Yulianeta et.al, (2016) meneliti repsesentasi dalam novel-novel Indonesia. Hasil penelitian menunjukkan adanya representasi ideologi patriarki, ideologi kekeluargaan, ideologi keibuan, dan ideologi gender. Penelitian yang dilakukan memiliki perbedaan dengan penelitian terdahulu. Pada penelitian ini membedah sosok kearifan lokal dalam budaya masyarakat Banten yang terrepresentasikan dalam novel. Kearifan lokal yang dideskripsikan adalah kearifan lokal jawara yang lekat dengan budaya kekerasan.

Berdasarkan latar belakang tersebut, dalam penelitian ini dideskripsikan representasi kearifan lokal jawara dalam novel Kelomang karya Qizink La Aziva dan membuat implikasinya bagi pendidikan karakter di Sekolah Menengah Atas, khususnya kelas XII. Kajian ini bertujuan untuk menggambarkan secara mendalam representasi kearifan lokal jawara dalam novel tersebut. Kemudian, dalam penelitian ini peneliti berusaha mendedah implikasinya bagi pendidikan karakter di Sekolah Menengah Atas, khususnya kelas XII.

\section{METODE}

Penelitian ini menggunakan metode yang bersifat deskriptif kualitatif. Metode deskriptif dapat diuraikan sebagai prosedur pemecahan masalah yang diselidiki dengan menggambarkan keadaan subjek atau objek penelitian pada saat sekarang berdasarkan fakta yang tampak atau sebagaimana adanya (Nawawi dalam Angreni \& Sari, 2017). Metode ini juga bertujuan untuk melukiskan secara sistematis fakta atau karakteristik subjek penelitian secara faktual dan cermat. Dalam penelitian ini metode tersebut digunakan untuk mendeskripsikan dan memahami gambaran kearifan lokal jawara dalam novel Kelomang karya Qizink La Aziva dalam perspektif sosiologi sastra.

Sumber data adalah novel Kelomang karya Qizink La Aziva, setebal 184 halaman, diterbitkan oleh PT Gramedia Pustaka Utama pada tahun 2016. Data yang digunakan dalam penelitian ini diperoleh melalui studi kepustakaan. Kepustakaan adalah sumber data yang diperoleh dari dokumen dengan mencari data-data mengenai hal-hal yang merupakan catatan, transkip, buku, majalah dan lain-lain yang menunjang penelitian. Data dalam penelitian ini adalah kalimatkalimat dalam kutipan teks dalam novel Kelomang karya Qizink La Aziva yang menggambarkan kearifan lokal jawara.

Pengumpulan data merupakan bagian yang penting dalam proses penelitian kualitatif. Pada proses pengumpulan data, dibutuhkan instrumen penelitian atau alat yang digunakan untuk mengumpulkan data. Pada penelitian ini menggunakan dua instrumen penelitian, yaitu: 1) peneliti sendiri (human instrument) dan 2) instrumen berupa kartu data. Validitas atau keabsahan merupakan kebenaran data dari penelitian. Validitas data dalam penelitian ini menggunakan validitas semantik. Adapun langkah-langkah kegiatannya sebagai berikut 1) membaca berkali-kali data penelitian, 2) membaca dan menelaah berbagai pustaka dan dokumen untuk memperoleh kecukupan rujukan, 3) mengamati secara cermat, terperinci dan teliti sebagai bentuk ketekunan pengamatan, dan 4) mengecek kepada teman sejawat atau informan yang memiliki keahlian di bidang sastra. 
Analisis data dilakukan dengan teknik deskriptif kualitatif melalui beberapa tahapan, yaitu 1) kategorisasi berdasarkan teori-teori yang penulis gunakan sebagai landasan penelitian, 2) tabulasi, dan 3) inferensi. Kategorisasi digunakan untuk mengelompokkan data berdasarkan kategori yang telah ditetapkan. Kemudian, penggunaan tabulasi digunakan untuk merangkum keseluruhan data dalam bentuk tabel. Lalu, inferensi digunakan untuk menginterpretasikan dan menyimpulkan hasil penelitian sesuai dengan permasalahan penelitian yaitu representasi kearifan lokal jawara dalam novel.

\section{HASIL DAN PEMBAHASAN}

Representasi kearifan lokal jawara dalam novel Kelomang karya Qizink La Aziva digambarkan melalui tokoh Sakib, Yanto, Ardi, dan Saija. Sosok jawara dalam novel ini memiliki ciri-ciri yaitu 1) jago beladiri, 2) bersifat pemberani, 3) berjiwa pemimpin, 4) bersenjatakan golok dan memakai batu akik 5) berbicara ceplas-ceplos, dan 6) budaya kekerasan.

\section{Jago Beladiri}

Sosok Yanto dan Saija dalam novel Kelomang karya Qizink La Aziva digambarkan memiliki kemampuan bela diri sebagaimana jati diri seorang jawara yang selalu membela keadilan.

Data 1

Untung saja Saija cukup sigap. Mendengar teriakan Ardi, tubuh Saija cepat berbalik. Tangan Saija lekas menangkap pergelangan tangan Ardi dan dengan sekali entakan, pisau itu terlepas dari genggaman Ardi. (Aziva, 2016: 120)

Data 2

Yanto berhasil mematahkan pukulan anak buah Sakib lainnya yang menyusul kemudian. Tak percuma dulu Yanto berjuang keras meraih sabuk hitam sehingga sekarang jago bela diri. (Aziva, 2016: 15)

Pada data (1) Saija yang merupakan juara kompetisi karate berhasil lolos dari serangan Ardi yang mengarahkan sebilah pisau komando ke arah tubuhnya. Dengan kesigapan yang layaknya seorang jawara yang jago bela diri, Saija berhasil menangkap pergelangan tangan Ardi, dan dengan sekali hentakan pisau itu terlepas dari genggaman Ardi. Gambaran jago beladiri muncul juga pada sosok tokoh Yanto (data 2). Sebagai seorang wartawan, Yanto sadar dirinya akan menghadapi risiko berhadapan dengan kekuasaan saat dirinya memberitakan kasus korupsi keluarga Sakib. Untungnya sedari muda Yanto berjuang keras untuk mendapatkan sabuk hitam bela diri. Dua tokoh dalam novel ini merepresentasikan sosok jawara yang didefinisikan sebagai orang yang memiliki kepandaian bermain silat untuk membela diri (Pribadi, 2013).

\section{Bersifat Pemberani}

Tokoh Ardi dan Yanto digambarkan sebagai sosok yang pemberani membela kebenaran dan kejujuran.

Data 3

Ia pernah merasakan dinginnya bilah golok anak buah Sakib di lehernya saat demo menentang dugaan nepotisme keluarga Sakib delapan tahun lalu. Saat itu ia sama sekali tak gentar. Untung saja golok itu tak sampai menebas batang lehernya karena ia keburu diamankan aparat kepolisian. (Aziva, 2016: 56) 
Data 4

"Aku bilang masukkan kembali uang itu ke tasmu!" amarah Yanto memuncak. Pemuda di depannya itu semakin kurang ajar saja. (Aziva, 2016: 91)

Data (3) menggambarkan tokoh Ardi sebagai seorang aktivis mahasiswa yang memiliki idealisme tinggi. Saat Ardi menjadi pemimpin demo menentang nepotisme keluarga Sakib, lehernya nyaris ditebas oleh anak buah Sakib. Akan tetapi, Ardi tidak takut akan tajamnya golok. Dia mengutamakan membela kepentingan masyarakat. Masyarakat yang tertindas oleh mengguritanya bisnis keluarga Sakib. Banyak kerabatnya yang menjadi penguasa di kota itu. Ketika penguasa dan pengusaha berkolaborasi untuk mencuri uang rakyat, maka rakyatlah yang jadi korban. Oleh karena itu, Ardi muncul sebagai seorang pemberani yang membela kepentingan rakyat dengan melakukan demo antinepotisme.

Pada data (4) sosok pemberani muncul pada tokoh Yanto yang menolak untuk disuap. Tindakan menyuap sudah merupakan budaya di keluarga Sakib. Keluarga Sakib rela menyuap agar kepentingannya dilaksanakan. Pada novel ini, sebagai pemimpin redaksi, Yanto bertanggung jawab atas isi berita koran Mata Pena. Koran ini memberitakan kasus korupsi yang dilakukan oleh salah seorang keluarga besar Sakib. Sosok jawara pada diri Yanto muncul sebagai orang yang selalu membela kepentingan masyarakat. Seorang jawara harus mempunyai sikap mental seorang pemberani melawan siapapun termasuk lawan sekuat apapun (Chairunnisa, 2017).

\section{Berjiwa Pemimpin}

Tokoh Sakib dan tokoh Saija digambarkan sebagai seorang sosok pemimpin bagi kelompoknya. Sakib digambarkan sebagai seorang pemimpin perusahaan yang memiliki banyak anak buah. Saija digambarkan senagai seorang pemimpin bagi pemuda yang peduli lingkungan.

Data 5

Sebatang cerutu terselip di sudut bibir Sakib. Pria setengah baya itu tahu betul cara menikmati lintingan tembakau yang panjangnya hampir sejengkal itu....Tiga orang duduk termangu di hadapan majikannya tersebut. Kepala mereka tertunduk, tak berani menatap wajah 'Si Tuan Besar.' (Aziva, 2016: 55)

Data 6

Sebagai ketua kelompok pecinta alam di kampusnya, Saija tak hanya sibuk mendaki gunung, menyusuri sungai, memanjat tebing, atau menjelajah guagua. Mahasiswa semester lima itu juga sering mengajak rekan-rekannya turun ke jalan untuk berdemo mengecam perusakan lingkungan. (Aziva, 2016: 33)

Tokoh Sakib (data 5) digambarkan seperti gambaran tokoh 'Godfather' pada cerita mafia di pulau Sardinia Italia. Dengan tubuh gempal dan cerutu selalu terselip di bibirnya, anak buahnya mengelilingi dirinya dan tidak ada satupun yang berani manatapnya. Mereka semua tertunduk tidak ada yang berani menatap karena takut. Bahkan anak buahnya sangat berhati-hati menghela napas, ketakutan suara tarikan nafas itu mengganggu kenikmatan Sakib mengisap cerutu. Tokoh Sakib digambarkan sebagai sosok yang kejam dan diktator. Gambaran sosok 
Sakib ini seperti sosok tokoh yang digambarkan pada film The Godfather karya Francis Ford Coppola. Tokoh Don dalam film tersebut memiliki sifat diktator, keputusannya tidak dapat digugat dan tidak ada alasan apapun untuk menolak perintahnya (Rumthe dan Zulaikha, 2017).

Sosok pemimpin yang berbeda direpresentasikan pada sosok tokoh Saija. Pada data (6) Saija merupakan ketua kelompok pecinta alam di kampusnya. Sebagai seorang pemimpin kelompok pecinta alam, Saija sering mengajak rekanrekannya turun ke jalan untuk berdemo mengecam kerusakan lingkungan di kota ini. Saija merupakan sosok pemimpin yang egaliter. Sosok Sakib direpresentasikan sebagai sosok jawara hitam dan sosok Saija sebagai sosok jawara putih. Hal ini sejalan dengan klasifikasi jawara menurut Firdausi (2016) yang menggolongkan jawara dari sudut perilakunya menjadi jawara putih dan jawara hitam. Jawara putih dianggap masih menghargai nilai-nilai etika kejawaraan dengan baik, sedangkan jawara hitam merupakan fenomena jawara yang ada saat ini yang selalu menghalalhan segala cara.

\section{Bersenjatakan Golok dan Memakai Batu Akik}

Sosok jawara digambarkan selalu menenteng golok segabai senjata utama yang digunakan untuk berkelahi membela kepentingan dirinya maupun kelompoknya. Tangan seorang jawara biasanya akan memakai batu akik yang besar-besar untuk menambah kesan sangar.

Data 7

Saat itu, penyidik langsung menyergap Bupati Jamaludin. Penyidik lainnya menyergap Sakib yang sedang menikmati cerutu di ruang tamu kamar itu. Sakib mencoba memberontak saat tangannya hendak diborgol. Ia mengambil sebilah golok yang terselip di balik bajunya. (Aziva, 2016: 175)

Data 8

Di kalangan anak buah Sakib beredar kabar bahwa rasa sakit dari tamparan Sakib bisa berdenyut beberapa hari. Apalagi saat Sakib mengenakan akik kesayangannya yang sudah diisi jampi-jampi oleh guru spiritualnya di Gunung Karang. (Aziva, 2016: 93)

Sebagai seorang jawara, pada data (7) digambarkan tokoh Sakib selalu menenteng golok di pinggangnya untuk berjaga-jaga di saat suasana genting. Menenteng golok di pinggang merupakan budaya agar sang jawara terlihat berwibawa dan sangar di depan lawannya. Ketika ditangkap, Sakib tidak menyerah begitu saja, ia memberontak melakukan perlawanan. Golok merupakan senjata tradisional masyarakat Banten (Chairunnisa, 2017). Masyarakat Banten mempercayai bahwa golok bukan hanya sebagai perkakas rumah tangga, akan tetapi memiliki nilai filosofi sebagai identitas kejantanan laki-laki (Mukhtar \& Nurjaman, 2019). Representasi sosok jawara pada diri tokoh Sakib (data 8) diperkuat gambarannya dengan aksesoris yang dipakai di tangannya yaitu batu akik yang sudah diisi jampi-jampi oleh guru spiritual 'dukun' di Gunung Karang. Batu akik bagi sebagian masyarakat memiliki makna simbolis sebagai lambang kekuasaan dan kemakmuran (Istiqomah, 2015). Umumnya masyarakat Indonesia masih mempercayai perdukunan dan ilmu hitam (Fadillah, Udu, \& Ibrahim, 2020).

Sosok jawara yang digambarkan pada novel ini sejalan dengan sosok jawara yang dideskripsikan oleh Hamid (2010) bahwa karakteristik jawara sangat unik, memakai seragam hitam-hitam, bersenjatakan golok di pinggangnya, dan 


$$
\begin{gathered}
\text { Indonesian Language Education and Literature } \\
\text { e-ISSN: } 2502-2261 \\
\text { http://www.syekhnurjati.ac.id/jurnal/index.php/jeill/ } \\
\text { Vol. 6, No. 2, Juli 2021, } 175 \text { - } 188
\end{gathered}
$$

kecenderungan menggunakan kekerasan dalam menyelesaikan masalah. Karena itu, bagi sebagian masyarakat, jawara dipandang sebagai sosok yang menakutkan.

\section{Berbicara Ceplas-ceplos}

Sosok Sakib sebagai seorang mantan kepala desa dan sekarang berprofesi sebagai pengusaha di berbagai bidang, ia memiliki gara bicara yang seenaknya (B. Sunda: sompral). Hal ini terkadang membuat mitra bicaranya merasa tersinggung. Bagi para anak buahnya, hal ini membuat fobia ketakutan di benak mereka. Data 9

Bila sedang kesal, Sakib suka bicara ceplas-ceplos yang biasa menyinggung Data 10 perasaan lawan bicaranya. (Aziva, 2016: 97)

"Maneh rek dicabok ku aing?" ucap Sakib sambal mengangkat telapak tangannya, bersiap-siap menampar Arya. (Aziva, 2016: 94)

Pada data (9) Sakib digambarkan oleh pengarang sebagai seorang yang suka bicara ceplas-ceplos tanpa dipikirkan terlebih dahulu apakah kata-katanya akan menyinggung perasaan orang lain. Sakib tak suka basa-basi. Bahkan, pada data (10) Sakib seolah mengancam kepada mitra bicaranya dengan mengatakan "Kamu mau saya tampar (Maneh rek dicabok ku aing)." Ujaran tersebut biasanya diujarkan oleh Sakib kepada anak buahnya yang gagal menjalankan perintah. Hal ini menambah kesan bahwa jawara itu sosok yang angker dan ditakuti. Gambaran jawara dalam novel ini sejalan dengan pendapat Alamsyah (2010) yang mengemukakan bahwa jawara memiliki karakter tertentu yang membedakan dirinya dari anggota masyarakat biasa. Karakter tersebut seperti wanten (berani), agresif, sompral (tutur kata keras dan seenaknya), memiliki keahlian bela diri, dan dianggap sebagai orang sakti (Chairunnisa, 2017).

\section{Budaya Kekerasan}

Tokoh Sakib digambarkan sebagai sosok jawara hitam yang selalu menghalalkan segala cara demi mencapai tujuannya. Sebagai seorang pengusaha besar, Sakib memiliki banyak uang dan juga banyak anak buah yang siap diperintah untuk melakukan kekerasan.

Data 11

"Aa tentu lebih tahu bagaimana watak orang kota ini yang lebih suka pakai otot ketimbang otaknya ketika menghadapi permasalahan," ungkap Citra. (Aziva, 2016: 47)

Data 12

Selain memanfaatkan jalur pemerintahan, Sakib juga tak sungkan menggunakan jalan kekerasan untuk mendapatkan proyek. Seringkali ia mengirimkan jawara ke kantor-kantor yang tak bisa diajak bisnis dengannya. (Aziva, 2016: 540)

Pada data (11) memberikan gambaran kultur budaya di kota yang menjadi latar novel yang lebih suka menggunakan ototnya daripada otaknya ketika menghadapi berbagai permasalahan. Data (12) memperkuat kesan bahwa Sakib lebih suka menyelesaikan permasalahan dengan cara kekerasan (cultural of violence) untuk mencapai tujuan bisnisnya. Biasanya dia mengerahkan para jawara yang menjadi anak buahnya untuk memberi tekanan kepada orang-orang yang tidak mau diajak berbisnis dengannya. Menurut Karomani (Sururi, 


\section{Indonesian Language Education and Literature e-ISSN: 2502-2261 \\ http://www.syekhnurjati.ac.id/jurnal/index.php/jeill/ Vol. 6, No. 2, Juli 2021, $175-188$}

Mardiana, \& Putri, 2020) budaya kekerasan dalam masyarakat Banten sangat identik dengan jawara yang menjadi subkultur masyarakat.

Kekerasan yang terjadi dalam novel ini lebih cenderung pada kekerasan struktural. Pengaruh Sakib didukung oleh koneksi yang dimilikinya dengan petinggi pemerintahan. Banyak kerabat Sakib yang duduk di lembaga pemerintahan. Bahkan di tingkat legislatif pun kerabatnya cukup menguasai. Organisasi kemasyarakatan juga telah dikuasai oleh ponakan-ponakan Sakib. Hal ini sejalan dengan pendapat Galtung (Eriyanti, 2017) yang membagi kekerasan menjadi dua, yaitu kekerasan langsung dan kekerasan tidak langsung. Kekerasan langsung (direct violence), yaitu kekerasan yang terjadi secara fisik, sedangkan kekerasan tidak langsung (invisible), yaitu kekerasan struktural (structural violence). Kekerasan langsung umumnya berhubungan dengan kekerasan verbal dan fisik yang terlihat sebagai perilaku. Kekerasan struktural adalah kekerasan tidak langsung, yang telah terbentuk dalam suatu sistem sosial tertentu. Oleh karena itu, penekanannya lebih condong kepada sistem yang berjalan dalam suatu situasi sosial.

\section{Implikasi Bagi Pendidikan Karakter di Sekolah}

Saat ini bangsa Indonesia sedang ditempa krisis multidimensional. Praktik korupsi, kolusi, dan nepotisme (KKN), penyalahgunaan obat-obatan, kekerasan dan tawuran remaja, tindakan intoleransi, dan aksi plagiasi merupakan hal yang lumrah terjadi pada bangsa kita. Hal tersebut dikarenakan adanya degradasi moral bangsa Indonesia. Penurunan moral yang dihadapi bangsa Indonesia merupakan salah satu faktor utama penghambat kemajuan negara. Mengatasi penurunan moral bangsa Indonesia merupakan kewajiban seluruh warga Indonesia. Salah satu cara untuk meminimalisir masalah tersebut adalah dengan memperkuat pendidikan karakter di sekolah. Oleh karena itu, pembentukan karakter siswa sangat penting dilaksanakan dengan sungguh-sungguh (Wulandari, 2015). Dalam mendukung tercapainya tujuan pendidikan karakter perlu adanya upaya komprehensif dengan melibatkan pemangku kepentingan dalam proses pendidikan karakter agar dapat tercapai secara maksimal (Ulger, Yigittir, \& Ercan, 2014).

Pembelajaran bahasa Indonesia dalam kurikulum 2013 adalah pembelajaran berbasis teks. Pembelajaran bahasa Indonesia bertujuan untuk meningkatkan keterampilan siswa dalam berkomunikasi, maka diperlukan materi yang dapat mendukung hal tersebut. Dalam hal ini, salah satu bahan pembelajaran yang dapat digunakan dalam proses belajar mengajar adalah karya sastra berupa teks novel. Karya sastra dapat disajikan sarana dalam pendidikan karakter siswa (Suryaman, 2010). Novel merupakan salah satu medium penyampaian pesan kepada pembaca mengenai tokoh, atau peristiwa tertentu agar pembaca mampu memahami dan mengambil amanat yang ada di dalamnya. Oleh karena itu, hasil penelitian dapat diimplikasikan dalam penguatan pendidikan karakter melalui karya sastra di sekolah. Hal demikian disebabkan karena di dalam Kurikulum 2013 terdapat komponen-komponen pembelajaran yang berkaitan dengan penguatan pendidikan karakter.

Untuk itu, guru harus mampu membuat skenario pembelajaran yang menyebabkan siswa dapat memahami isi teks novel sehingga pada akhirnya siswa dapat mengambil amanat yang terkandung dalam novel Kelomang karya Qizink La Aziva. Kearifan lokal dapat digunakan sebagai cermin tingkah laku dalam upaya peningkatan kecerdasan emosional melalui pendidikan karakter di sekolah (Kusnita et.al, 2017). Siswa dapat meneladani nilai kejujuran yang tergambar 
pada tokoh Yanto yang berani menolak saat akan disuap sejumlah uang. Ataupun mencontoh tokoh Saija, seorang pemuda yang sangat peduli pada lingkungan sekitarnya sehingga ia rela berdemonstrasi untuk menolak penambangan pasir laut. Siswa dapat menghindari sikap menghalalkan segala cara yang direpresentasikan pada tokoh Sakib.

Kegiatan pembelajaran yang wajib dilaksanakan oleh guru dan siswa di kelas XII sesuai kompetensi inti (KI) dan kompetensi dasar (KD) dilaksanakan sesuai langkah-langkah berikut ini. Kegiatan awal: a) guru dan siswa saling memberi salam; b) guru memberikan apersepsi mengaitkan keadaan alam di sekitar sekolah dengan materi pembelajaran; c) guru memberikan pengantar materi dasar memahami teks novel agar membantu siswa dalam kegiatan inti; dan d) guru memberikan motivasi belajar kepada siswa. Kemudian, kegiatan inti: a) guru membuat kelompok belajar yang terdiri atas enam orang; b) siswa mempelajari dan menalar materi mengenai teks novel dan menghubungkannya dengan peristiwa kerusakan alam; c) siswa dalam masing-masing kelompok ditugaskan untuk mengidentifikasi karakter tokoh yang terdapat pada teks novel tersebut; d) guru meminta siswa untuk menanggapi teks novel berdasarkan karakteristik tokoh yang ada; e) guru meminta siswa untuk menukar hasil kerja antarkelompok; dan f) masing-masing kelompok ditugasi untuk mengidentifikasi karakteristik tokoh yang dapat diteladani. Adapun kegiatan akhir: a) guru bersama-sama siswa menyimpulkan inti dari proses pembelajaran yang telah berlangsung; b) guru memberikan motivasi dan penghargaan atas kinerja siswa; dan c) guru memberikan pengayaan berupa tugas membaca teks novel, kemudian saling mengucapkan salam dengan siswa.

Tabel 1.

Kompetensi Inti dan Kompetensi Dasar Kelas XII

\begin{tabular}{|c|c|c|c|}
\hline $\begin{array}{l}\text { Kompetensi Inti } \\
\text { (Pengetahuan) }\end{array}$ & $\begin{array}{l}\text { Kompetensi Inti } \\
\text { (Keterampilan) }\end{array}$ & $\begin{array}{c}\text { Kompetensi } \\
\text { Dasar } \\
\text { (Pengetahuan) }\end{array}$ & $\begin{array}{c}\text { Kompetensi } \\
\text { Dasar } \\
\text { (Keterampilan) }\end{array}$ \\
\hline $\begin{array}{l}\text { Memahami, menerapkan, menganalisis } \\
\text { dan mengevaluasi pengetahuan } \\
\text { faktual, konseptual, prosedural, dan } \\
\text { metakognitif berdasarkan rasa ingin } \\
\text { tahunya tentang ilmu pengetahuan, } \\
\text { teknologi, seni, budaya, dan humaniora } \\
\text { dengan wawasan kemanusiaan, } \\
\text { kebangsaan, kenegaraan, dan } \\
\text { peradaban terkait penyebab fenomena } \\
\text { dan kejadian, serta menerapkan } \\
\text { pengetahuan prosedural pada bidang } \\
\text { kajian yang spesifik sesuai dengan } \\
\text { bakat dan minatnya untuk } \\
\text { memecahkan masalah }\end{array}$ & $\begin{array}{l}\text { Mengolah, menalar, } \\
\text { menyaji, dan mencipta } \\
\text { dalam ranah konkret } \\
\text { dan ranah abstrak } \\
\text { terkait dengan } \\
\text { pengembangan dari } \\
\text { yang dipelajarinya di } \\
\text { sekolah secara mandiri } \\
\text { serta bertindak secara } \\
\text { efektif dan kreatif, dan } \\
\text { mampu menggunakan } \\
\text { metoda sesuai kaidah } \\
\text { keilmuan }\end{array}$ & $\begin{array}{l}\text { Menafsir } \\
\text { pandangan } \\
\text { pengarang } \\
\text { terhadap } \\
\text { kehidupan } \\
\text { dalam novel } \\
\text { yang dibaca }\end{array}$ & $\begin{array}{l}\text { Menyajikan } \\
\text { hasil } \\
\text { interpretasi } \\
\text { terhadap } \\
\text { pandangan } \\
\text { pengarang } \\
\text { baik secara } \\
\text { lisan maupun } \\
\text { tulis }\end{array}$ \\
\hline
\end{tabular}

\section{SIMPULAN}

Jawara adalah elite yang dikonstruksi oleh budaya Banten. Masyarakat Banten pernah mengalami tekanan sosial dan politik yang sangat dalam dan lama sehingga menciptakan budaya kekerasan yang peran utamanya dimainkan oleh sosok jawara. Kemampuannya memanipulasi kekuatan supranatural dan 


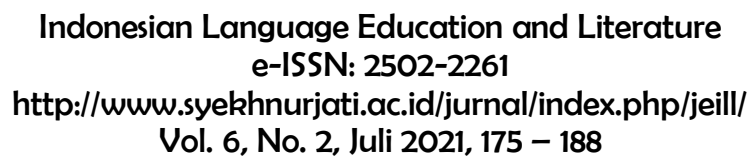

keunggulan dalam hal fisik telah membuatnya jadi sosok yang ditakuti sekaligus dikagumi, sehingga terkadang muncul menjadi tokoh yang kharismatik dan heroik. Peranannya juga tidak hanya terbatas kepada guru persilatan, ilmu kesaktian atau jasa pengamanan tetapi juga sebagai pemimpin sebuah pergerakan sosial. Bahkan untuk saat ini, jawara memiliki peran penting dalam sosial politik masyarakat Banten. Dalam novel ini muncul sosok jawara hitam yang tergambar pada sosok Sakib yang selalu menghalalkan segala cara demi mendapatkan tujuannya. Sebaliknya, sosok jawara putih tergambar pada sosok tokoh Saija yang berjuang demi kepentingan masyarakat. Hasil penelitian ini dapat diimplikasikan dalam pembelajaran bahasa Indonesia di Sekolah Menengah Atas, khususnya kelas XII. Hal demikian disebabkan karena di dalam Kurikulum 2013 terdapat komponen-komponen pembelajaran yang berkaitan dengan penguatan pendidikan karakter. Siswa dapat meneladani karakter baik pada tokoh-tokoh yang ada pada novel tersebut.

\section{DAFTAR PUSTAKA}

Alamsyah, A. R. (2010). Islam, Jawara, dan Demokrasi. Jakarta: PT Dian Rakyat. Angreni, S., \& Sari, R.T. (2017). Ketersediaan dan Pemanfaatan Media Komponen Instrumen Terpadu (KIT) IPA di SD Negeri Kecamatan Nanggalo Kota Padang. Jurnal Pendidikan Dasar Nusantara, 2(2), 234-242. Diunduh dari https://ojs.unpkediri.ac.id/index.php/pgsd/article/view/557

Ato'ullah. (2014). Jawara dalam Perubahan Sosial di Masyarakat Banten. Jurnal Ilmiah Mimbar Demokrasi, 13(2), 25-38. https://doi.org/10.21009/jimd.v13i2.6413

Aziva, Q. L. (2016). Kelomang. Jakarta: PT Gramedia Pustaka Utama.

Barker, C. (2015). Cultural Studies: Teori dan Praktik. Yogyakarta: Kreasi Wacana.

Cahyo, A. D. (2017). Representasi Makna Jawara dalam Film "Jawara Kidul” : Analisis Semiotika Roland Barthes. Skripsi. Universitas Siltan Ageng Tirtayasa. Tidak Diterbitkan.

Chairiyani, R. P. (2012). Representasi Seksualitas dalam Novel Saman Karya Ayu Utami. Humaniora, 3(2), 363-372.

Chairunnisa, F. (2017). Representasi Jawara dalam Kearifan Lokal pada Film 'JawaraKidul'. Skripsi. IAIN Sultan Maulana Hasanudin Banten. Tidak Diterbitkan.

Damono, S. D. (2013). Sosiologi Sastra. Jakarta: Editum.

Dewi, W. O. S., \& Balawa, L.O. (2017). Kritik Sosial dalam Novel Surat Cinta Untuk Kisha Karya Bintang Berkisah. Jurnal Bastra, 1(4), 1-13.

Eriyanti, L. D. (2017). Pemikiran Johan Galtung tentang Kekerasan dalam Perspektif Feminisme. Jurnal Hubungan Internasional, 6(1), 1-11. https://doi.org/10.18196/hi.61102

Fadillah, Udu, S., \& Ibrahim, I. (2020). Kekerasan Budaya dalam Novel Kutukan Tanah Buton Karya Safarudin: Sosiologi Sastra. Jurnal Pendidikan Bahasa, 9(2), 37-47.

Firdausi, I. A. (2016). Jawara dalam Budaya Banten: Studi Etnografi Komunikasi Mengenai Jawara di Banten. Jurnal Lontar, 4(2), 15-25. https://doi.org/10.30656/lontar.v4i3.361 
Hamid, A. (2010). Memetakan Aktor Politik Lokal Banten Pasca Orde Baru: Studi Kasus Kiai dan Jawara di Banten. Politika, 1(2), 32-45. https://doi.org/10.1117/12.817903

Hasanah, F. (2017). Representasi Femme Fatale dalam Novel Cantik Itu Luka karya Eka Kurniawan. Poetika: Jurnal Ilmu Sastra, 5(1), 14-25. https://doi.org/10.22146/poetika.v5i1.25446

Ilma, A. A. (2016). Representasi Penindasan Ganda dalam Novel Mirah dari Banda Berdasarkan Perpektif Poskolonial. Poetika: Jurnal Ilmu Sastra, 4(1), 3-11. https://doi.org/10.22146/poetika.v4i1.13310

Istiqomah, N., Doyin, M., \& Sumartini. (2014). Sikap Hidup Orang Jawa dalam Novel Orang-Orang Proyek Karya Ahmad Tohari. Jurnal Sastra Indonesia, 3(1), 1-9.

Istiqomah, S. (2015). Fenomena Batu Akik pada Masa Orde Baru di Masyarakat GunungKidul dalam Novel Maya Karya Ayu Utami: Kajian Antropologi Sastra. Jurnal Sastra Indonesia, 4(1), 1-10.

Kusnita et al. (2017). The role of local wisdom in the Malay folklore Mempawah as base of character education on children in primary school. ASSEHR, 158, 649-656.

Mandrastuty, R. (2010). Novel 'Tarian Bumi' Karya Oka Rusmini: Kajian Feminisme. Skripsi. Universitas Sebelas Maret. Tidak Diterbitkan.

Mu'jizah. (2014). Representasi Anak dalam Karya Arswendo Atmowiloto: Studi Cerita Anak Tahun 1970-an. Kandai, 10(2), 231-245. https://doi.org/10.26499/jk.v10i2.326

Mukhtar, R. H. \& Nurjaman, A. (2019). Nilai Budaya Sunda dalam Novel Jawara Angkara di Bumi Krakatau Karya Fatih Zam Sebagai Upaya Pengayaan Bahan Ajar pada Pembelajaran Sastra di Sekolah. Pedagogia: Jurnal Ilmiah Pendidikan, 11(1), 6-22.

Mukti, W. I., Andayani, A., \& Wardani, N. E. (2018). Potrait of Pesantren Education in Novel Ayat-Ayat Cinta 2 (Potret Pendidikan Pesantren dalam Novel Ayat-Ayat Cinta 2). Indonesian Language Education and Literature, $3(2), 181-195$.

Nurgiyantoro, B. (2011). Teori Pengkajian Fiksi. Yogyakarta: UGM Press.

Pribadi, Y. (2013). Another side of Islam in Banten: The socio-political roles of Jawara during the New Order era 1966-1998. Journal of Indonesian Islam, 7(2), 314-336. https://doi.org/10.15642/JIIS.2013.7.2.314-336

Pribadi, Y. (2011). Strongmen and religious leaders in Java: Their dynamic relationship in search of power. Al-Jami'ah, 49(1), 159-190. https://doi.org/10.14421/ajis.2011.491.159-190

Pujiati, H. (2018). Representasi Radikalisme dan Deradikalisme Agama dalam Sastra Pesantren. Adabiyyat: Jurnal Bahasa dan Sastra, 2(1), 73-98. https://doi.org/10.14421/ajbs.2018.02104

Rumthe, L. R. D., \& Zulaikha. (2017). Makna Keluarga pada Kelompok Mafia: Analisis Semiotika pada Film The Godfather. Jurnal Kajian Media, 1(1), 28-41. http://dx.doi.org/10.25139/jkm.v1i1.163

Sari, P. S. \& Nuryatin, A. (2017). Representasi Perempuan Bali dalam NovelNovel Karya Oka Rusmini. JP-BSI: Jurnal Pendidikan Bahasa dan Sastra Indonesia, 2(2), 44-48. http://dx.doi.org/10.26737/jp-bsi/v2i2.241 
Setiawan, A., Agustina, E., \& Chanafiah, Y. (2019). Analisis Tokoh Utama dalam Novel Rose in The Rain Karya Wahyu Sujani. Jurnal Ilmiah Korpus, 3(2), 123-130. https://doi.org/10.33369/jik.v3i2.10112

Sukarjo, W. (2014). Kritik Sosial Terhadap Sistem Hukum dalam Novel Bukan Karena Kau Karya Toha Mohtar: Sebuah Tinjauan Sosiologis. Humanika, 20(2), 9-23. https://doi.org/10.14710/humanika.20.2.9-23

Supriyantini, \& Arifin, E. Z. (2019). Nilai Pendidikan dan Moral dalam Novel Dendam Si Yatim Piatu Karya Sintha Rosse. Jurnal Pujangga, 5(1), 47-75. http://dx.doi.org/10.47313/pujangga.v5i1.731

Sururi, A., Mardiana, S., \& Putri, L. D. (2020). Cultural Transformation and Revitalization Identity of Banten Jawara. Humanika, 27(1), 1-10.

Suryaman, M. (2010). Pendidikan Karakter Melalui Pembelajaran Sastra. Cakrawala Pendidikan, 29 (edisi khusus), 112-126.

Tihami, M. A. (2015). Kiyai dan Jawara Banten: Keislaman, Kepemimpinan, dan Magis. Refleksi, 14(1), 1-24. https://doi.org/10.15408/ref.v14i1.9575

Ulger, Y., Yigittir, S., \& Ercan, O. (2014). Secondary School Teachers Beliefs on Character Education Competency. Procedia Social and Behavioral Sciences, 131, 442-449.

Wiyatmi. (2013). Representasi Sejarah Indonesia dalam Novel-novel Ayu Utami. LITERA, 2(2), 209-223. https://doi.org/10.21831/ltr.v12i02.1545

Wulandari, R. A. (2015). Sastra dalam Pembentukan Karakter Siswa. Jurnal Edukasi Kultura, 2(2), 63-73. https://doi.org/10.24114/kultura.v1i2.5181

Yulianeta, Soeratno, S. C., \& Kusharyanto, J. (2016). Representation of Gender Ideology in Indonesia Novels: A Study of The Reformation Era Novel. Lingua Cultura, 10(1), 31-36. https://doi.org/10.21512/lc.v10i1.845

Zulu, N. S. (2012). Gender and Cultural Representations in the Sesotho Novel. Journal of Literary Studies, 28(2), 58-67. https://doi.org/10.1080/02564718.2012.676338 